\title{
SARUBICIN B, A NEW QUINONE ANTIBIOTIC, ISOLATED FROM THE FERMENTATION BROTH OF
}

\section{A STREPTOMYCES STRAIN}

\author{
Klaus Eckardt, Dieter Tresselt, Wolfgang Ihn, Gertraud Bradler \\ and G. REINHARDT
}
Akademie der Wissenschaften der DDR, Zentralinstitut für Mikrobiologie und Experimentelle Therapie, DDR-69 Jena, Beutenbergstraße 11, DDR

(Received for publication September 1, 1982)

\begin{abstract}
Sarubicin B, isolated from the culture filtrate of a Streptomyces strain JA 2861, is a new quinone antibiotic. The compound was isolated as an orange crystalline powder, mp $282 \sim$ $284^{\circ} \mathrm{C}$. In vitro sarubicin B was found to inhibit Gram-positive bacteria. It was not active against Gram-negative microorganisms.
\end{abstract}

In a previous communication we reported on the antibiotic sarubicin A which was isolated from the culture filtrate of Streptomyces violaceoruber strain JA 2861'1). Structural studies have shown that sarubicin $\mathrm{A}$ is a new quinone antibiotic ${ }^{2)}$. This paper describes the properties of a minor component designated as sarubicin B.

\section{Experimental}

Fermentation and Isolation

Fermentation conditions and isolation of the crude material were as described ${ }^{1)}$. The orange material mainly consisting of sarubicin A was chromatographed on a silica gel column $\left(\mathrm{KH}_{2} \mathrm{PO}_{4^{-}}\right.$ buffered silica gel, $30 \times 3 \mathrm{~cm}$ ). Elution was with ethyl acetate. Sarubicin B was the first yellow band which was clearly separated from other red and yellow minor bands and the main red component sarubicin A. The corresponding fractions obtained from several columns containing sarubicin B were combined and concentrated to a small volume. The antibiotic precipitated as an orange crystalline substance.

\section{Mass Spectroscopy}

Mass spectra were recorded on a JEOL JMS-D 100 spectrometer at $75 \mathrm{eV}$, direct inlet system, heated at $160^{\circ} \mathrm{C}$. Exact mass measurements were performed using the peak matching method (PFK as standard).

Antibacterial Activity

The minimum inhibitory concentrations (MIC) of the antibiotic were determined for various bacteria by the agar plate diffusion method. Samples of sarubicin B were dissolved in DMSO and diluted with methanol to the final concentration.

\section{Results}

Physical and Chemical Properties

Sarubicin B is an orange crystalline antibiotic. It is soluble in dimethyl sulfoxide, less soluble with yellow color in most common organic solvents and only weakly soluble in water. The color in concentrated $\mathrm{H}_{2} \mathrm{SO}_{4}$ and in $\mathrm{NaOH}$ is yellow. The crystalline compound melts at $282 \sim 284^{\circ} \mathrm{C}$. The mass spec- 
Fig. 1. Electron impact mass spectrum of sarubicin B.

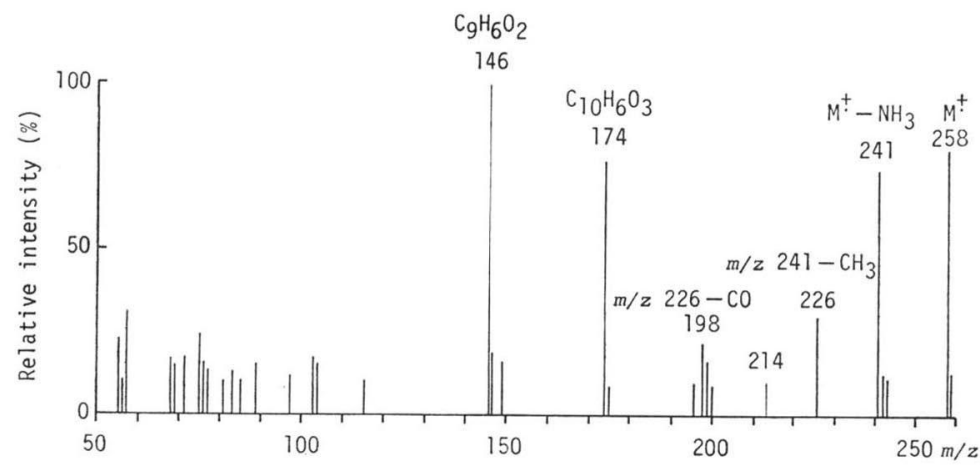

Fig. 2. Infrared spectrum of sarubicin $B(\mathrm{KBr})$.

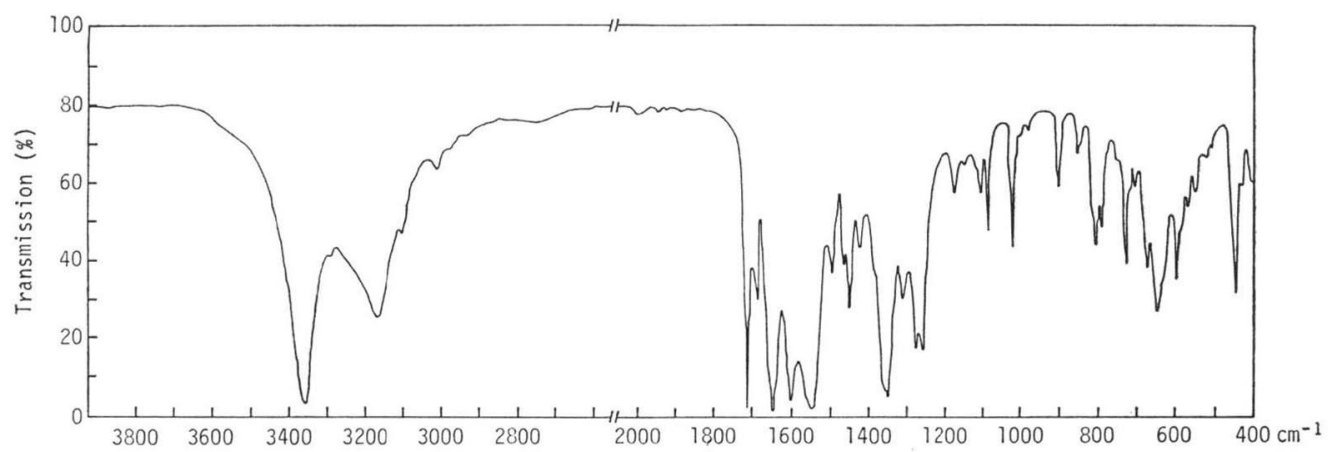

Fig. 3. Structure of sarubicin B.<smiles>CC(=O)c1cccc2c(=O)c(C(N)=O)cccc12</smiles>

trum (Fig. 1) shows a molecular ion at $m / z 258$. The accurate mass measurement for this peak gave a value of 258.0625 indicating a molecular formula of $\mathrm{C}_{13} \mathrm{H}_{10} \mathrm{~N}_{2} \mathrm{O}_{4}$ (Calcd. 258.0640). The ultraviolet absorption spectrum of sarubicin B in methanol has maxima at 232, 275, 349 and 434 nm. Fig. 2 shows the infrared absorption spectrum of sarubicin $\mathrm{B}(\mathrm{KBr})$. The spectrum shows characteristic absorptions at 3355 and $3170 \mathrm{~cm}^{-1}$ $\left(-\mathrm{NH}_{2}\right)$ and at $1712,1645,1600$ and $1545 \mathrm{~cm}^{-1}\left(\mathrm{C}=\mathrm{O}\right.$, quinone, $\left.-\mathrm{CONH}_{2}\right)$. Structural elucidation studies of sarubicin B, details of which will be published elsewhere ${ }^{3)}$, have indicated that the antibiotic has structure as shown Fig. 3.

\section{Biological Properties}

The antimicrobial activity against a variety of bacteria is given in Table 1. Sarubicin B has a mo- 
derate activity against Gram-positive bacteria. No activity could be found when the antibiotic was tested against a number of Gram-negative bacteria, yeasts or fungi.

\section{Discussion}

Crude mixtures of sarubicin A which were extracted from the culture filtrate of the Streptomyces violaceoruber strain JA 2861 were found to be accompanied by several minor components exhibiting similar or better antibiotic properties as the main compound. One of these satellite compounds has been purified by column chromatography and studied with regard to its chemical and biological properties. Like sarubicin A the new antibiotic sarubicin B belongs to the quinone type of antibiotics. According to the described physical properties and its structure the compound is not identical with similar antibiotics described in literature.

\section{References}

1) Reinhardt, G.; G. Bradler, K. Eckardt, D. Tresselt \& W. Ihn: Isolation and characterization of sarubicin A, a new antibiotic. J. Antibiotics 33: 787 790, 1980

2) Tresselt, D.; K. Eckardt, W. Ihn, L. Radics \& G. Reinhardt: Antibiotika aus Aktinomyceten. Zur chemischen Konstitution des Antibiotikums Sarubicin A. Tetrahedron 37: 1961 1965, 1981

3) Tresselt, D.; K. Eckardt \& W. Ihn: Zur chemischen Struktur des Antibiotikums Sarubicin B. Manuscript in preparation. 